\title{
Formação de professores no contexto do mestrado profissional em educação da UFSCar
}

\section{Teacher education in the context of professional master's program in education of the UFSCar}

\author{
Maria do Carmo de Sousa ${ }^{1}$ \\ Dulcimeire Aparecida Volante Zanon ${ }^{2}$
}

\section{Resumo}

Este artigo é decorrente de um estudo qualitativo, de cunho teórico e caracterizado como documental. Tem como objetivo discutir as relações entre as questões que conduziram as pesquisas dos professores da Educação Básica, inseridos no âmbito do Mestrado Profissional em Educação da UFSCar, e as respostas que foram elaboradas e explicitadas por eles nas considerações finais, tecidas nos Trabalhos de Conclusão de Curso, no formato de Dissertação. Os resultados indicam que os questionamentos dos professores referem-se ao estudo de diversas temáticas, dentre elas, o ensino de língua portuguesa no Brasil e suas relações com os documentos $\mathrm{PCN}$ e BNCC; o jogo e o conceito de número na Educação Infantil; o desenvolvimento profissional docente; a contextualização dos conteúdos de Física no Ensino Médio; o ensino de meios audiovisuais; e as articulações entre a identidade étnicoracial e a identidade profissional. As considerações finais revelam aspectos que se relacionam com suas indagações, dadas as oportunidades de revisão e de teorização do ensino que ministram. Ressaltamos que se fazem necessárias ampliar os olhares e as discussões sobre as implicações práticas das pesquisas geradas nos cursos de Mestrado Profissional em Educação.

Palavras-chave: Formação de professores; Pesquisas de professores; Mestrado Profissional em Educação; Dissertação de Mestrado.

\begin{abstract}
This documentary article is the result of a qualitative theoretical study. It aims to discuss the relationships established between the questions made by Basic Education teachers, wich the scope of the Professional Master's Program in Education of the UFSCar, and the answers that

\footnotetext{
${ }^{1}$ Doutora em Educação pela Universidade Estadual de Campinas (UNICAMP). Docente do Programa de PósGraduação Profissional em Educação da Universidade Federal de São Carlos, UFSCar, São Carlos, SP, Brasil. E-mail: mdcsousa@ufscar.br

${ }^{2}$ Doutora em Educação pela Universidade Federal de São Carlos (UFSCar). Docente do Programa de PósGraduação Profissional em Educação da Universidade Federal de São Carlos, UFSCar, São Carlos, SP, Brasil. E-mail:dulci@ufscar.br
} 
were elaborated and explained by them in the final considerations, woven in the Course Conclusion Papers, in the Dissertation format. The results indicate that the teachers' questions refer to the study of several themes, among them, the teaching of Portuguese in Brasil and its relations with the PCN and BNCC documents; the game and the concept of number in Early Childhood Education; the professional development of teachers; the contextualization of physics content in high school; teaching audiovisual media; and the links between ethnic and racial identity and professional identity. Final considerations reveal aspects that are related to their inquiries, given the opportunities for reviewing and theorizing the teaching they teach. We emphasize that it is necessary to expand the views and discussions on the practical implications of the research generated in the Professional Master's Program in Education courses.

Keywords: Teacher education; Researches of teachers; Professional Master's Program in Education; Masters dissertation.

\section{Introdução}

A formação continuada dos professores da Educação Básica no contexto brasileiro pode acontecer por meio de cursos de diferentes naturezas e duração que ocorrem em níveis de graduação e pós-graduação lato e stricto sensu. No que diz respeito à formação stricto sensu, os professores podem optar pela modalidade acadêmica ou profissional.

De acordo com o Parecer do Conselho Nacional de Educação (BRASIL, 2009), os Mestrados Profissionais (MP), que já foram denominados de profissionalizantes, tendem a buscar sua identidade na produção de conhecimentos em torno de um objeto comum, direcionada para sua qualificação. Assim, o MP é um importante lócus formativo para os docentes da Educação Básica já que, por meio da imersão na pesquisa, visa formar um professor-pesquisador que tenha condições de ser protagonista de sua formação e transformação profissional (RIBEIRO, 2005, 2006). Sendo assim,

a pesquisa nos mestrados profissionais da área deve observar essa dupla dimensão da educação, área de conhecimento e área de atuação profissional, tratando assim da produção de conhecimento comprometido com o agir intencional, que implica compreensão fundamentada e refletida das práticas, com vistas às possibilidades de sua transformação (AMBROSETTI; CALIL, 2016, p. 89).

Em relação à temática pesquisa e formação de professores, Oliveira, Moura e Silva (2020, p. 417) também destacam a essencialidade e a transformação pela qual o professor da 
Educação Básica e da Universidade podem passar por meio de discussões, pois "possibilita aos sujeitos um retorno ou continuidade de formação continuada que tem como um dos pontos cruciais a pesquisa e o ato reflexivo acerca, seja da sua prática, ou da realidade vivida; o que causa mudanças em sua prática docente".

Lüdke, Cruz e Boing (2009), por sua vez, salientam a importância da cooperação entre o professor da Educação Básica e o da Universidade na elaboração de projetos pelo fato de propiciar condições para desenvolver pesquisas mais próximas e significativas para o contexto escolar. Ademais, "é preciso compreender a realidade e as práticas que ali se realizam, o que só é possível por meio da mediação teórica que pode dotar de significados e de conteúdos interpretativos" (SILVA, 2017, p. 132).

Dessa forma, a pesquisa tem um importante papel na formação do docente, pois permite a ele analisar criticamente a realidade do seu contexto de trabalho, para, fazer uso dela em sua prática profissional. A atitude de pesquisador é promovida quando o professor formula questões sobre seu contexto profissional, busca dados e referências para elucidar as questões que o intrigam, trata os dados e expressa seus achados. Essas ações implicam diversos aprendizados como o da problematização e da argumentação. Portanto, a particularidade da pesquisa desenvolvida nos mestrados profissionais direciona o olhar para o cotidiano escolar e educacional (ANDRÉ, 2016).

Segundo Stenhouse (1975, 1981), professor-pesquisador é aquele que, como um artista, busca as melhores maneiras de atingir os estudantes no processo de ensino e aprendizagem. Para tanto, faz uso de diferentes materiais e procura soluções mais adequadas para sua criação. Neste caso, visa entender as particularidades da circunstância educativa, a fim de transformar a própria prática em objeto de investigação para que possa aprimorá-la. Schön (1983, 1992), por sua vez, concebe o professor como aquele que produz conhecimentos, reflete sobre sua prática e, com base nestas reflexões, promove mudanças em sua ação, em suas salas de aula ou em outros ambientes de aprendizagem. Sendo assim, há certa similaridade de paradigma entre o professor pesquisador e o professor reflexivo, já que, para ambos, os objetivos consistem em formar um professor que reflete sobre sua própria prática e assume sua realidade escolar como um objeto de pesquisa, de reflexão e de análise. Ao mesmo tempo, Fagundes (2016, p. 295) considera que é possível descrever o conceito de professor-pesquisador, como parte de um processo de pesquisa, no qual 
a) estejam implicados professores ou professores e pesquisadores que, produtores do conhecimento que são, buscam compreender a natureza dos fenômenos educativos em razão da necessidade de aprendizado dos alunos e de sua formação humana;

b) sejam consideradas a interculturalidade e a pluralidade como partes inerentes à sociedade e aos sujeitos que se desenvolvem nela;

c) a reflexão seja concebida como processo humano que se dá, individual e coletivamente, em busca de entendimento a respeito dos diferentes aspectos sociais, psicológicos, afetivos, políticos e educacionais.

Entendemos, tal como Nogueira, Neres e Brito (2016, p. 66), que a "concepção de professor-pesquisador representa uma ideia de movimento, num continuиm" e que "o foco principal da formação stricto sensu para a o professor da educação básica é garantir a unidade teoria e prática" (OLIVEIRA; MOURA; SILVA, 2020, p. 420).

A partir dos pressupostos apresentados nos parágrafos anteriores, elaboramos este manuscrito, com o como objetivo de discutir as relações entre as questões que conduziram as pesquisas dos professores da Educação Básica, inseridos no âmbito do Mestrado Profissional em Educação (MPE) da UFSCar, e as respostas que foram elaboradas e explicitadas por eles nas considerações finais, tecidas nos Trabalhos de Conclusão de Curso, no formato de Dissertação.

Cabe destacar que os questionamentos, aos quais nos referimos, são decorrentes das vivências dos mestrandos em sala de aula transformadas em problemáticas de pesquisa, à medida em que participavam das atividades promovidas no MPE da UFSCar. Ou seja, o estudo, que se propõe a responder à pergunta: "quais relações podem ser estabelecidas entre as questões que conduziram as pesquisas dos professores da Educação Básica e as respostas que foram explicitadas em suas dissertações?" pode contribuir com as investigações que tem como objeto de estudo a formação continuada de professores brasileiros, uma vez que, no contexto do MPE da UFSCar, ao elaborarem respostas aos seus questionamentos, os professores têm a oportunidade de teorizar sobre suas práticas e praticar as teorias que fundamentam as aulas que ministram. Podem se tornar professores-pesquisadores, tendo a prática de sala de aula como objeto de estudo.

\section{O MPE no contexto da política nacional de formação de professores no Brasil: breve} histórico

Ao tratarmos de políticas públicas que envolvem a formação de professores no Brasil

Revista Devir Educação, Lavras, vol.2, n.4, p.104-125 jul./dez., 2020. 
não há como negar que, de modo geral, elas têm sido sempre emergenciais, conforme apontam os estudos de Freitas (2007). Especificamente, no que diz respeito à formação continuada dos professores da Educação Básica, a autora afirma que, ao longo de duas décadas, o Brasil vem tentando seguir as indicações dos organismos internacionais no sentido de pensar modelos de formação que possam ser feitos a distância e com redução de custos.

A forma adotada pelos sistemas de ensino, desde 2000, para a formação superior dos professores em exercício na educação básica, responde, como indicamos em 2003 (Freitas, 2003), à recomendação dos organismos internacionais para a formação de professores, como forma de atender massivamente à demanda emergente por formação, com custos reduzidos. Introduz os tutores, mediadores da formação, supervisionados por docentes universitários, alterando radicalmente a concepção e o caráter do trabalho docente no ensino superior. A iniciativa de localizar os pólos presenciais em vários municípios, com a presença circunstancial dos estudantes, representou novas formas de organização da formação, mediante concessão de bolsas a professores das próprias redes de educação básica ou a pós-graduandos, para atuarem como tutores, e se desenvolveu, no período de 2003-2006, em continuidade à política adotada para a formação continuada de professores. Este modelo, desenvolvido a distância através de mídias interativas e novas tecnologias da informação e comunicação, se organiza em projetos de cursos que partem do trabalho dos professores, exclusivamente em sua dimensão prática, reduzindo as possibilidades da mediação pedagógica necessária no processo de ensino, e não se sustenta quando confrontado com as condições de produção da vida material e da organização da escola e da educação, que demandam outras habilidades, capacidades e competências de seus educadores. Estudos recentes (Araújo, 2007; Chueire, 2005), analisam experiências de formação desenvolvidas por universidades, em cursos com estas características, e apontam suas potencialidades e limites na ascensão a processos mais elevados de formação humana e profissionalização. Este ainda é um campo em desenvolvimento na área da educação (FREITAS, 2007, p. 1209).

Para além dos cursos a distância e da redução dos custos, ao nos apresentar esse contexto, no campo da pós-graduação, Freitas (2007, p. 1211) não deixa de criticar o movimento denominado de "secundarização do conhecimento teórico do campo epistemológico da educação e sua mediação pedagógica”. Além disso, discute a

[...] nova configuração que vem se dando à pós-graduação da área, a partir de 2000, com a criação dos cursos de pós-graduação em ensino de ciências e matemática, na área multidisciplinar, separados da área de educação na CAPES, com a abertura de mestrados profissionais na área da formação de professores, separados dos mestrados acadêmicos da área da educação (FREITAS, 2007, p. 1211).

Revista Devir Educação, Lavras, vol.2, n.4, p.104-125 jul./dez., 2020. 
Ou seja, no período em questão, a partir de 2000, em um primeiro momento, não havia indicações de que os cursos de ciências e matemática seriam implementados no formato a distância e não foi feita nenhuma menção no que diz respeito aos Mestrados Profissionais em Educação (MPE). Estes ainda não estavam sendo criados. Naquele momento, Freitas (2007) estava se referindo aos mestrados profissionais em rede, considerando-se que

[...] o aumento e fortalecimento, junto a diferentes programas, da criação dos mestrados profissionais são indicadores dos novos contornos que podem adquirir as políticas de formação, articulando a UAB e a CAPES, como nova agência reguladora da formação de professores. A CAPES, juntamente com o FNDE, no financiamento, e o INEP, na avaliação da educação básica, compõe o tripé das agências reguladoras no campo da educação (FREITAS, 2007, p. 1217).

Assim, as políticas nacionais de formação de professores, pela primeira vez, no Brasil, procuravam se articular com a Universidade Aberta do Brasil (UAB) e a Coordenação de Aperfeiçoamento de Pessoal de Nível Superior (CAPES). No entanto, essa articulação que se apresenta nos mestrados profissionais em rede, até hoje, desaparece quando colocamos o foco da discussão nos mestrados profissionais em educação.

Ao analisarmos a trajetória estes últimos, concordamos com André e Princepe (2017, , p. 104) que afirmam

[...] os mestrados profissionais em educação têm uma trajetória bastante curta e sua implantação vem sendo marcada por muita controvérsia, muitos impasses, resistências e desconfianças. O primeiro curso da área foi aprovado em 2009, mas só começou a funcionar em 2010, enquanto em outras áreas do conhecimento essa trajetória começou muito mais cedo.

Ao responderem sobre o porquê de "tantas dúvidas, tantas objeções" quanto à implementação dos mestrados profissionais em educação no Brasil, as autoras supracitadas, ponderam que as discussões "no âmbito da Associação Nacional de Pesquisa e PósGraduação em Educação (ANPEd), que levaram os pesquisadores a assumir uma posição de resistência frente à possibilidade de criação dos mestrados profissionais na área da educação, com receios similares àqueles expressos por Severino", giravam em torno de dois argumentos: a perda do "espaço da pesquisa e o nível de qualidade conquistado pela pósgraduação brasileira" (ANDRÉ; PRINCEPE, 2017, p. 104). Tanto as objeções quanto as 
resistências foram sendo quebradas à medida que esses cursos começaram a "ganhar força e credibilidade".

\begin{abstract}
Isso se deve principalmente à forma aguerrida com que os cursos de mestrado profissional vêm se articulando, o que deu origem ao Fórum de Mestrados Profissionais em Educação (FOMPE), que reúne coordenadores dos mestrados profissionais da área, desde 2014, constituindo um espaço de discussões, que tem sido essencial para definir metas comuns e critérios de qualidade para os cursos de mestrado profissional. Os posicionamentos que vêm sendo assumidos pelos participantes do FOMPE, sob a forma de relatórios técnicos, artigos publicados em revistas da área, encaminhamentos à coordenação de área da CAPES têm contribuído para que os preconceitos e as resistências, ainda presentes em alguns grupos da comunidade acadêmica, venham diminuindo ou desaparecendo (ANDRÉ; PRINCEPE, 2017, p. 105).
\end{abstract}

As pesquisadoras ainda chamam a atenção para o fato de que, dentre as temáticas abordadas no FOMPE,

[...] destaca-se a identidade dos mestrados profissionais. (HETKOWISKI, 2016; ROMÃO; MAFRA, 2016). O texto de Hetkowiski (2016), que retoma muitos documentos produzidos, indica que a identidade dos Mestrados Profissionais se expressa nas linhas de pesquisa e na proposta curricular dos programas, assim como nos trabalhos finais de conclusão, que devem se voltar para a atividade profissional dos mestrandos (ANDRÉ; PRINCEPE, 2017, p. 105).

Ou seja, desde que os mestrados profissionais em educação passaram a fazer parte da política nacional da pós-graduação brasileira, não há como negar a sua identidade, nem o aumento no número de programas. Ao consultarmos os documentos da CAPES e a página do FOMPE, para analisar a situação dos programas de pós-graduação, no período de 2009 a 2018, constatamos que o número de programas e cursos relacionados a esse curso específico teve um aumento significativo, na última década, conforme mostra o Quadro 1.0.

Quadro 1.0 - Cursos reconhecidos e avaliados pela CAPES - 2017

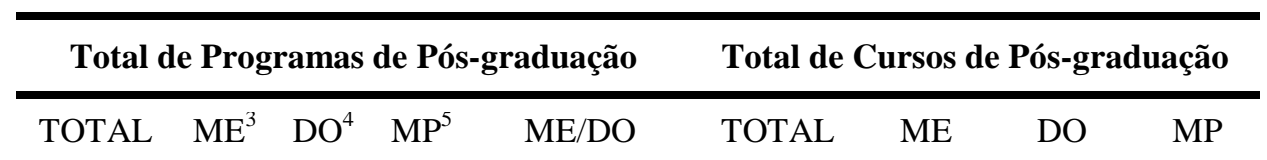

\footnotetext{
${ }^{3}$ ME: Mestrado

${ }^{4}$ DO: Doutorado

${ }^{5}$ MP: Mestrado Profissional
}

Revista Devir Educação, Lavras, vol.2, n.4, p.104-125 jul./dez., 2020. 


\begin{tabular}{|c|c|c|c|c|c|c|c|c|}
\hline \multicolumn{5}{|c|}{ Total de Programas de Pós-graduação } & \multicolumn{4}{|c|}{ Total de Cursos de Pós-graduação } \\
\hline 176 & 54 & 0 & 46 & 76 & 252 & 130 & 76 & 46 \\
\hline
\end{tabular}

Podemos constatar que, até 2017, o número de programas de pós-graduação profissional em Educação coincidia com número de cursos de MPE: 46. Dos 252 cursos de pós-graduação existentes até aquele momento, no Brasil, 46 deles pertenciam à categoria profissional, o que equivalia a 18\% do total dos cursos, em nível de Mestrado e Doutorado.

Há de se considerar ainda que os dados do relatório da avaliação quadrienal da CAPES (p. 87-92) de 2017 indicam que, dos 46 cursos de Mestrado Profissional, 42 foram avaliados e estão distribuídos em 41 instituições de ensino superior (IES) espalhadas por todo o País, conforme Quadro 2.0:

Quadro 2.0 Distribuição de programas profissionais por região - 2018

\begin{tabular}{cccccc}
\hline Estrato & Norte & Nordeste & Sudeste & Sul & Centro-Oeste \\
\hline 3 & 0 & 5 & 9 & 3 & 1 \\
4 & 1 & 7 & 10 & 5 & 1 \\
\hline Total & 1 & 12 & 19 & 8 & 2 \\
\hline \multicolumn{5}{c}{ Fonte: CAPES (2018) }
\end{tabular}

O Quadro 2.0 informa que boa parte desses cursos, ou seja 19, deles, estão localizados na região sudeste, o que equivalia, em 2017, a $41 \%$ do total. Ao analisarmos as perspectivas dos mestrados profissionais em educação, a partir dos dados que foram apresentados, não há como discordar de Fialho e Hetkowski (2017, p. 26), que afirmam:

[...] os MPE são, eles mesmos, uma nova perspectiva, não apenas no que eles podem promover, mas no próprio processo que implicou concebê-los, darlhes forma, desenhar arranjos institucionais. Trata-se de um processo de dinâmica social, que implica instituir algo que não está dado, por vezes em meio a confrontos com o já existente, num contexto de debates, tensões, retrocessos, polêmicas, revisões, aprofundamentos e avanços. Dessa forma, compreendemos que, no cenário brasileiro, no âmbito dos MPE, alguns conjuntos de temáticas se fizeram presentes, ora anunciando novas perspectivas (a exemplo dos encaminhamentos relativos à atualização da Ficha de Avaliação e da reafirmação do compromisso com a educação

Revista Devir Educação, Lavras, vol.2, n.4, p.104-125 jul./dez., 2020. 
básica), ora reiterando princípios e conquistas (como ilustra a defesa do rigor da avaliação, da composição do quadro docente formado por doutores e da pesquisa como fundamento de todo o processo formativo).

Esta nova perspectiva que se apresenta a partir dos mestrados profissionais em educação aponta para a necessidade de repensar questões que considerem temáticas relevantes relacionadas à formação, à identidade e à prática docente, já que, nesse contexto, a pesquisa é considerada "como fundamento de todo processo formativo" dos professores da Educação Básica (FIALHO; HETKOWSKI, 2017, p. 26).

Sendo assim, neste texto, a formação docente é entendida como processo permanente e envolve a valorização identitária e profissional dos professores. Sua identidade é simultaneamente epistemológica e profissional, realizando-se no campo teórico do conhecimento e no âmbito da prática social. E a transformação da prática docente decorre da ampliação da consciência crítica do professor sobre ela. Portanto, aprimorar a qualidade do trabalho escolar é tarefa complexa, uma vez que os professores contribuem com seus saberes, seus valores e suas experiências no fazer e pensar o ensino, através da elaboração de pesquisas.

Ademais, faz-se necessário chamar atenção para o enfrentamento dos desafios das situações de ensino, o que exige do profissional da Educação competência no conhecimento disciplinar e interdisciplinar, sensibilidade ética e consciência política (BRASIL, 2001). Por esse motivo, temos defendido que os programas e, consequentemente, os professores da Educação Básica sejam amparados por financiamento, quando desenvolvem pesquisas nos contextos dos mestrados profissionais em educação. Sobreviver sem financiamentos - eis um desafio e tanto para todos os envolvidos.

\section{O MPE da UFSCar: contribuições para a formação de professores da Educação} Básica

A proposta para a criação do Programa de Pós-Graduação Profissional em Educação (PPGPE) da UFSCar foi apresentada para a CAPES, em 2011, por docentes do Departamento de Metodologia de Ensino (DME) que atuam na formação de professores e em pesquisas das diversas áreas do conhecimento, como Biologia, Filosofia, Física, Educação Física, Letras, Matemática, Música, Pedagogia e Química. Após aprovada, o curso teve início no segundo 
semestre de 2013.

O mestrado profissional em educação da UFSCar possui uma única linha de pesquisa, intitulada "Processos educativos - Linguagens, Currículo e Tecnologias", e tem como objetivo geral oferecer formação no nível de pós-graduação profissional como continuidade da formação de professores já atuantes na Educação Básica, em diferentes áreas do conhecimento. Nesse sentido, tem por finalidade possibilitar ao pós-graduando condições para desenvolver práticas profissionais reflexivas articuladas com as novas demandas da Educação Básica. Alinhados a esse objetivo geral, são propostos os seguintes objetivos específicos: 1) contribuir com a formação continuada de professores da Educação Básica; 2) promover a parceria entre escola e universidade, de forma que a escola seja considerada lócus de formação de professores e produtora de conhecimento; 3) favorecer o desenvolvimento profissional dos professores da Educação Básica, como processo que se dá ao longo da carreira; 4) viabilizar ações que possibilitem aos professores da Educação Básica desenvolver postura investigativa como professores-pesquisadores; 5) incentivar ações investigativas que permitam aos professores da Educação Básica refletir sobre a possibilidade de efetuar um trabalho compartilhado na perspectiva interdisciplinar; e 6) valorizar a articulação entre os conhecimentos produzidos no ensino superior e na educação básica, resultando em benefícios para um aprendizado mais reflexivo para professores em exercício e em propostas metodológicas e de inovações pedagógicas para as escolas nas quais os envolvidos atuam. Assim, o público-alvo são os professores que já atuam na Educação Básica em qualquer área de conhecimento.

Nesta perspectiva, o mestrado profissional em educação da UFSCar pretende propiciar que os professores em exercício compreendam melhor os princípios epistemológicos que sustentam suas ações, possibilitando ratificar suas práticas com maior consciência ou reformulá-las. Tal movimento poderá suscitar, como impacto a curto e médio prazo, abordagens didáticas mais comprometidas e situadas sócio-historicamente e a elaboração de materiais e recursos didáticos inovadores, com otimização de linguagens e tecnologias. $\mathrm{O}$ impacto que, a longo prazo, um curso dessa natureza poderá implicar é uma postura de maior valorização do magistério e da profissão docente e melhor compreensão sobre aspectos vivenciados nos processos de ensino e aprendizagem nas escolas da educação básica, além de novas reflexões e teorizações. Há de se ressaltar, ainda, que o mestrado profissional em educação da UFSCar visa realizar pesquisas com os professores, a partir de situações didáticas

Revista Devir Educação, Lavras, vol.2, n.4, p.104-125 jul./dez., 2020. 
situadas, contextualizadas e de caráter interdisciplinar; e estabelecer, assim, a tão necessária parceria entre Universidade e Escola, de forma que os professores da Educação Básica possam ser reconhecidos socialmente como produtores de conhecimento. Ao mesmo tempo, a Escola pode ser também reconhecida como mais um lócus de produção de conhecimentos e formadora de professores.

Com efeito, o mestrado profissional em educação da UFSCar busca superar o caráter formalista de formação de professores, ao propor a articulação dos conteúdos abordados à investigação da sala de aula e a integração curricular dos tópicos teóricos com as vivências de professores da Educação Básica. Sendo assim, pressupõe-se que haja articulação entre saberes teóricos e saberes da experiência, em um movimento de mútua recriação da teoria na prática e da prática na teoria. Tal movimento fundamenta-se em alguns dos documentos norteadores para a formação de professores, por exemplo, o Parecer CNE/CP 9/2001, as Diretrizes curriculares nacionais para a formação de professores da educação básica em nível superior, o Plano de Desenvolvimento da Educação (PDE), dentre outros.

As disciplinas que compõem a grade curricular possuem, dentre seus princípios metodológicos, a apresentação de situações-problema aos pós-graduandos, para que compreendam as injunções de ordem histórica, política e social que as determinam e abstraiam princípios - epistemológicos, metodológicos, didáticos - que embasam suas ações e, simultaneamente, fortalecem suas teorizações. O total de créditos para a titulação é 100, sendo 36 para as disciplinas ( 2 obrigatórias e 4 optativas) e 64 para a elaboração do trabalho final que tem como formato a dissertação.

No período de 2014 a 2019 houve 68 dissertações defendidas, conforme Quadro 3.0:

Quadro 3.0 - Informações sobre as dissertações defendidas - 2014 a 2019.

\begin{tabular}{lcccccc}
\hline Dissertações & $\mathbf{2 0 1 4}$ & $\mathbf{2 0 1 5}$ & $\mathbf{2 0 1 6}$ & $\mathbf{2 0 1 7}$ & $\mathbf{2 0 1 8}$ & $\mathbf{2 0 1 9}$ \\
\cline { 2 - 7 } $\begin{array}{l}\text { defendidas } \\
\text { por ano }\end{array}$ & 01 & 12 & 12 & 11 & 16 & 16 \\
\hline TOTAL & & & & & \\
\hline
\end{tabular}

Fonte: Plataforma Sucupira (2020).

Para a escrita deste relato, fizemos um recorte das pesquisas de 2019. Consideramos as 


\section{OO DEVIR EDUCAÇÃO}

ISSN: 2526-849X

16 produções na linha do Programa "Processos educativos - Linguagens, Currículo e Tecnologias", as quais tiveram como foco as seguintes linguagens: Arte; Biologia, Ciências e Educação Ambiental; Currículo; Física; Gestão; Matemática e Pedagogia.

\section{Metodologia do estudo}

Este manuscrito é decorrente de um estudo qualitativo e de cunho teórico que pode ser caracterizado como documental, com inspiração em "estudos tipicamente históricos", conforme apontam Fiorentini e Lorenzato (2007, p. 103), considerando-se que, para levantarmos as informações necessárias, fizemos uso de fontes primárias, tais como: textos teóricos e dissertações elaboradas por professores da Educação Básica, no contexto do PPGPE.

A fim de atingirmos o objetivo deste texto, inicialmente selecionamos 6 , das 16 dissertações defendidas no ano de 2019, as quais foram denominadas de: D1, D2, D3, D4, D5 e D6 a fim de preservarmos a identidade dos autores. A escolha se deu pela representatividade nas diferentes linguagens: Arte, Língua Portuguesa; Matemática; Ciências; Física e Pedagogia. O critério de escolha está atrelado ao cumprimento do prazo da defesa. Os professores da Educação Básica desenvolveram suas pesquisas no prazo previsto para o MPE da UFSCar, em 24 meses.

Ao desenvolvermos o estudo, elegemos uma metodologia composta dos seguintes momentos e estratégias:

$\left.1^{\circ}\right)$ Análise histórica do conteúdo: consistiu de um estudo teórico sobre a história dos conceitos tratados nas políticas nacionais de formação de professores, com especial atenção para o mestrado profissional e o mestrado profissional em educação. O estudo remeteu, necessariamente, a uma pesquisa bibliográfica que envolveu tanto as investigações sobre formação de professores quanto as relações existentes entre formação de professores e programas de pós-graduação.

$2^{\circ}$ ) Análise de dissertações: fundamentou-se na leitura das dissertações defendidas no contexto do PPGPE, no ano de 2019.

Dessa forma, a análise dos dados seguiu uma linha interpretativa cuja característica é “a particularização, ao invés da generalização de resultados. A busca não é de universais abstratos, aos quais se chega, segundo Moreira (1990), a generalizações estatísticas, mas sim

Revista Devir Educação, Lavras, vol.2, n.4, p.104-125 jul./dez., 2020. 
de universais concretos, que se atinge através do estudo detalhado de um caso específico, localizado culturalmente" (LANNER DE MOURA, 1995, p. 69). Por esse motivo, a interpretação nos permitiu organizar pelo menos dois eixos temáticos: 1) relações entre os questionamentos realizados pelos professores que geram suas pesquisas com o memorial que compõe a dissertação e 2) relações entre os questionamentos realizados pelos professores que geram suas pesquisas com as considerações finais tecidas nas dissertações.

O primeiro eixo temático nos remeteu à construção da problemática da pesquisa pelos professores. No caso do MPE da UFSCar é através da escrita do memorial que os professores indicam que seus questionamentos não surgem ao acaso. De modo geral, estão relacionados às suas vivências enquanto ex-alunos da Educação Básica ou do Ensino Superior e/ou profissionais da educação bem como das teorias implícitas que regem suas ações.

Já, o segundo eixo indicou que os questionamentos iniciais apresentados no memorial podem ser modificados, na medida em que os professores cursavam as disciplinas obrigatórias e optativas. Passaram a compreendem melhor que toda prática é cotejada pela teoria e, toda teoria é cotejada pela prática.

Priorizaremos o segundo eixo, ainda que os dois estejam interligados, formando uma unidade dialética.

\section{Um olhar sobre as pesquisas defendidas no âmbito do MPE da UFSCar}

Ao analisarmos as seis dissertações, defendidas pelos professores da Educação Básica, do PPGPE da UFSCar, em 2019, constatamos que as temáticas envolvem discussões e reflexões que ocorrem no cotidiano da escola.

Os professores estão interessados em teorizar sobre práticas que se materializam em questionamentos, as quais envolvem: 1) o ensino de língua portuguesa no Brasil e suas relações com os documentos PCN e BNCC (D1); 2) o jogo e o conceito de número na Educação Infantil (D2); 3) desenvolvimento profissional docente (D3); 4) contextualização dos conteúdos de Física no Ensino Médio (D4); 5) ensino de meios audiovisuais (D5) e 6) articulações entre a identidade étnico-racial e a identidade profissional (D6), conforme mostra o Quadro 4.0.

Quadro 4.0 - Relação entre as temáticas, as questões de pesquisa e as considerações finais

Revista Devir Educação, Lavras, vol.2, n.4, p.104-125 jul./dez., 2020. 


\begin{tabular}{|c|c|c|}
\hline Dissertações & Questões das pesquisas & Considerações finais \\
\hline D1 & $\begin{array}{l}\text { a) Quais sentidos sobre a } \\
\text { LP como objeto de } \\
\text { ensino são construídos } \\
\text { pelos PCN (BRASIL, } \\
\text { 1998) e pela BNCC } \\
\text { (BRASIL, 2017)? } \\
\text { b) De que forma os } \\
\text { sentidos materializados } \\
\text { nos PCN (BRASIL, } \\
\text { 1998) se relacionam com } \\
\text { aqueles materializados } \\
\text { na BNCC (BRASIL, } \\
\text { 2017)? (p. 36) }\end{array}$ & $\begin{array}{l}\text { Ao desenvolver nossa pesquisa, pudemos compreender um pouco } \\
\text { mais acerca da importância da análise discursiva de documentos } \\
\text { oficiais, arquivo, que prescrevem o ensino da língua no Brasil, } \\
\text { como forma de evidenciar os deslizes de sentidos em relação à } \\
\text { língua portuguesa como objeto de ensino de dominação e } \\
\text { exploração, de relação de força. Essas evidências produziram e } \\
\text { produzem equívocos, ao nosso ver, tomando a língua como um } \\
\text { mecanismo político de imposição de uma base nacional comum } \\
\text { com o discurso de melhoria do sistema educacional no Brasil para } \\
\text { todos os grupos da sociedade. Para tanto, as ações } \\
\text { governamentais devem ser reais, efetivas e urgentes a fim de } \\
\text { atenderem às inúmeras demandas e carências da educação pública } \\
\text { brasileira. (p. 185) Retomando a epígrafe desse capítulo, } \\
\text { entendemos que ao longo da pesquisa muitos sentidos foram } \\
\text { descontruídos, reconstruídos, ressignificados, apagados, } \\
\text { silenciados, enfim, muitos outros foram significados e postos } \\
\underline{\text { neste trabalho com o afinco de fazer sempre o melhor e contribuir }} \\
\text { para a produção científica, a fim de que os leitores desta pesquisa } \\
\underline{\text { de mestrado possam, nessa perspectiva discursiva, lançar um }} \\
\text { olhar, gestos de interpretação, deslocar os sentidos sobre o ensino } \\
\underline{\text { de língua portuguesa, sobre a educação brasileira, e acreditar que }} \\
\underline{\text { nós, professores, pesquisadores somos agentes capazes de instigar }} \\
\text { e promover movimentos para que haja realmente um ensino de } \\
\text { qualidade a todos no Brasil, no intuito de respeito à diversidade } \\
\text { linguística e propiciar oportunidades aos discentes de terem } \\
\text { práticas pedagógicas possíveis de aprendizagem, rompendo com } \\
\text { os discursos de privilegiar a homogeneidade da língua } \\
\text { materializados nos documentos oficiais. (p. 190) }\end{array}$ \\
\hline D2 & $\begin{array}{l}\text { Como se manifestam } \\
\text { nexos conceituais } \\
\text { (internos e externos) que } \\
\text { se apresentam no } \\
\text { conceito de número, por } \\
\text { crianças da Educação } \\
\text { Infantil, durante uma } \\
\text { situação desencadeadora } \\
\text { de aprendizagem? (p. } 8 \text { ) }\end{array}$ & $\begin{array}{l}\text { Como resultado principal desta dissertação, foi possível concluir, } \\
\text { através das categorias de análise aqui estabelecidas: noções de } \\
\text { quantidade e qualidade, senso numérico, correspondência um-a- } \\
\text { um, agrupamento e ordenação, que os nexos conceituais de } \\
\text { número apresentados pelos alunos se dão em diferentes níveis de } \\
\text { compreensão. Os alunos conseguem compreender a relação entre } \\
\text { o número e a quantidade com auxílio da pesquisadora. Durante o } \\
\text { jogo foi observado que as crianças, ao estabelecerem uma noção } \\
\text { de quantidade colocam em desenvolvimento um elo } \\
\text { representativo com os demais nexos conceituais do número o que } \\
\text { auxilia a sistematização do conceito de número. Deste modo } \\
\text { presume-se que o trabalho pedagógico com o jogo de boliche na } \\
\text { perspectiva HC pode reforçar e contribuir para o desenvolvimento } \\
\text { mais efetivo das noções numéricas para crianças em estágio de } \\
\text { educação infantil. Quanto ao senso numérico pudemos verificar } \\
\text { que o mesmo sendo um nexo numérico interno está relacionado a } \\
\text { quantidade. Isso fica foi evidenciado quando ao final do jogo as } \\
\text { crianças ao serem questionadas sobre quem ganhou, indicaram } \\
\text { todas a mesma Equipe sem se utilizarem da contagem. Ao } \\
\text { olharmos para correspondência um a um, percebemos que essas } \\
\text { crianças ainda não desenvolveram esse nexo numérico, isso fica } \\
\text { evidenciado quando fazem a associação de que cada risquinho } \\
\text { marcado na lousa representa um pino derrubado, entretanto isso } \\
\text { só foi possível com a intervenção da pesquisadora. Sobre o } \\
\text { agrupamento e ordenação verificou-se que são nexos ainda não } \\
\text { estabelecidos por essas crianças já que necessitam da ajuda da } \\
\text { pesquisadora para justificarem sobre que Equipe ganhou o jogo e } \\
\text { estão diretamente ligados as noções quantidade e de senso }\end{array}$ \\
\hline
\end{tabular}




\begin{tabular}{|c|c|c|}
\hline & & $\begin{array}{l}\text { numérico. Mesmo com nossa intencionalidade e cuidado com } \\
\text { planejamento detalhado do plano de aula e da aplicação do jogo } \\
\text { de boliche, buscando possibilitar a emergência dos nexos } \\
\text { conceituais de número durante uma situação desencadeadora de } \\
\text { aprendizagem, entendemos que dada a complexidade do objeto } \\
\text { estudado, tem-se o desafio do desenvolvimento de outras técnicas } \\
\text { e métodos que possam ser usadas em pesquisas futuras. (p. } 91 \text { ) }\end{array}$ \\
\hline D3 & $\begin{array}{l}\text { Quais são } \\
\text { contribuições de us } \\
\text { proposta de formação } \\
\text { colaborativa baseada na } \\
\text { reflexão sobre o ensino } \\
\text { de Ciências na } \\
\text { perspectiva CTS para o } \\
\text { desenvolvimento } \\
\text { profissional docente? } \\
\text { (p.8) }\end{array}$ & $\begin{array}{l}\text { Podemos sintetizar algumas, a saber: o reconhecimento do } \\
\text { processo de aprendizagem da docência como um continuum ao } \\
\text { longo da carreira; a importância da interação com pares que } \\
\text { favorece a atribuição de significado para as novas experiências e } \\
\text { as anteriores, ou seja, ao desenvolvimento profissional; o } \\
\text { levantamento de problemas sobre a prática e a busca de soluções } \\
\text { para as dificuldades enfrentadas; a promoção de reflexões de } \\
\text { forma sistemática, rigorosa e disciplinada que exigem valorização } \\
\text { de atitudes de ambas as partes - pesquisadora e professora; o } \\
\text { encorajamento de situações inusitadas, incertas, conflituosas } \\
\text { sobre novas formas de atuação. Por outro lado, entendemos que } \\
\text { uma das dificuldades e/ou limitações enfrentadas para a } \\
\text { consolidação da proposta de formação colaborativa foi "colocar } \\
\text { no papel todo esse estudo e pesquisa em conjunto para } \\
\text { transformar essa elaboração em atividades visando a } \\
\text { aprendizagem de forma efetiva" (Maria, Quest. Final 4). Do } \\
\text { ponto de vista da execução da situação didática na perspectiva } \\
\text { CTS foi o "tempo escasso e muito corrido, mas principalmente, } \\
\text { de conciliar as atividades do projeto com as atividades da apostila } \\
\text { com o mesmo tema". A apostila aborda o conteúdo sobre o } \\
\text { sistema solar de forma breve, enquanto que no "projeto } \\
\text { aprofundou mais e foi dividido por partes e principalmente seguiu } \\
\text { toda uma lógica de atividades para que desse aos alunos meios } \\
\text { para entender e aprender sobre cada planeta" (Maria, Quest. Final } \\
\text { 5). (p.89) }\end{array}$ \\
\hline D4 & $\begin{array}{l}\text { Qual a relação que os } \\
\text { alunos estabelecem com } \\
\text { a contextualização dos } \\
\text { conteúdos da física a } \\
\text { partir de uma atividade } \\
\text { experimental de } \\
\text { investigação? (p. 19) }\end{array}$ & $\begin{array}{l}\text { A partir da análise dos dados coletados foi possível separar as } \\
\text { relações estabelecidas pelos estudantes de acordo com as } \\
\text { perspectivas de contextualização: Aproximação com o cotidiano, } \\
\text { Relação do conteúdo com outras áreas do conhecimento } \\
\text { Interdisciplinaridade e Busca por novos conhecimentos } \\
\text { científicos. Essas categorias revelaram que os alunos } \\
\text { estabeleceram uma certa relação com situações presentes em seus } \\
\text { cotidianos, tentaram articular seus conhecimentos prévios com o } \\
\text { fenômeno, os quais poderiam estar contextualizados também em } \\
\text { outras disciplinas e para buscarem novos conhecimentos } \\
\text { científicos. No entanto, percebemos que os alunos não tiverem } \\
\text { interesse pelo conteúdo específico de circuitos elétricos, e sim } \\
\text { pelo fenômeno eletricidade, uma vez que trouxeram exemplos de } \\
\text { situações cotidianas que precisavam de energia para se trabalhar. } \\
\text { Notamos que os alunos gostaram da atividade, falaram que era } \\
\text { interessante por terem participado de uma dinâmica diferente e } \\
\text { por terem a oportunidade de se trabalhar com uma atividade } \\
\text { prática e de forma investigativa. Porém os estudantes não } \\
\text { perceberam a contextualização presente nela, visto que mesmo } \\
\text { havendo um cuidado em trazer elementos que fizessem parte do } \\
\text { cotidiano deles (como a pilha, o fio, a lâmpada etc.), eles tiveram } \\
\text { dificuldade em fazer essa relação. (p. 62-63) }\end{array}$ \\
\hline D5 & $\begin{array}{l}\text { Quais são os limites e } \\
\text { possibilidades }\end{array}$ & $\begin{array}{l}\text { Percebo que durante as aulas foi possível trabalhar e valorizar os } \\
\text { gostos dos alunos ao trabalhar com a realidade deles, discutir }\end{array}$ \\
\hline
\end{tabular}




\begin{tabular}{|c|c|c|}
\hline & $\begin{array}{l}\text { interculturalidade como } \\
\text { referencial de aulas de } \\
\text { Arte no Ensino médio? } \\
\text { (p. 14) }\end{array}$ & $\begin{array}{l}\text { alteridade além de trabalhar a tolerância entre as opiniões. } \\
\text { Também foi possível observar que houve a construção de uma } \\
\text { produção simbólica, onde a partir da criação da própria vinheta, } \\
\text { os alunos produziram simbolicamente sobre o assunto que era } \\
\text { pertinente para eles: a preocupação com o futuro. Ressalto mais } \\
\text { uma vez, a importância de se observar as práticas em sala de aula. } \\
\text { Na maioria das vezes, só me dei conta de coisas que pretendo } \\
\text { modificar em minha prática docente quando tive a oportunidade } \\
\text { de assistir minhas gravações, como pesquisadora. Este fato } \\
\text { corrobora o que escrevi no início destas considerações finais: } \\
\text { trabalhar buscando a interculturalidade no ensino exige muito } \\
\text { estudo e análise da própria prática, pois muitas atitudes } \\
\text { desfavorecem essa prática, por serem automáticas e passarem } \\
\text { despercebidas em sala de aula. (p. 125) }\end{array}$ \\
\hline D6 & $\begin{array}{l}\text { Como é a trajetória } \\
\text { identitária do diretor de } \\
\text { escola negro quando num } \\
\text { processo de assunção de } \\
\text { um cargo de chefia em } \\
\text { escolas municipais na } \\
\text { cidade de São Paulo? (p. } \\
\text { 15) }\end{array}$ & $\begin{array}{l}\text { Nesse momento de finalização do estudo é importante ressaltar } \\
\text { pontos importantes que encontramos no percurso, isso porque, os } \\
\text { autores com quem dialogamos e os diretores de escola nos } \\
\text { trouxeram para uma perspectiva muito além do que começamos. } \\
\text { Ao retomarmos a pergunta que norteia a pesquisa - "Como é a } \\
\text { trajetória identitária do diretor de escola negro quando num } \\
\text { processo de assunção a um cargo de chefia?" - observamos que } \\
\text { esse processo segundo os diretores que conhecemos e } \\
\text { conversamos foi marcado por muitas histórias importantes desde } \\
\text { a infância, e que estar ocupando um cargo de chefia exige alguns } \\
\text { saberes e a disposição para aprender e buscar caminhos para os } \\
\text { desafios diários. (p. 145). Nossa pesquisa nesse processo de } \\
\text { conclusão demonstra que a ascensão a cargos de chefia pela } \\
\text { população negra é processual e necessária, as leis de reparação e } \\
\text { ações afirmativas chegam com atraso, mas que bom que } \\
\text { chegaram, pois a luta não termina com a promulgação da lei, e os } \\
\text { dados que trouxemos até aqui demonstram essa perspectiva. } \\
\text { Tentamos até aqui mostrar que apesar das dificuldades o negro é } \\
\text { capaz de exercer qualquer atividade, e sua ascensão social ainda } \\
\text { que estatisticamente pequena em relação a ascensão social dos } \\
\text { brancos é fundamental para a representatividade racial. As } \\
\text { crianças negras precisam ver exemplos para se sentirem } \\
\text { incentivadas, e irem em busca de melhores condições de vida. } \\
\text { Assim, as políticas públicas são necessárias para a igualdade de } \\
\text { condições para todos que desejarem. (p. 150) }\end{array}$ \\
\hline
\end{tabular}

Fonte: Repositório Institucional UFSCar (2020). Grifos nossos.

Ao analisarmos o Quadro 4.0, constatamos que, no caso específico da D1, o foco dos questionamentos está nos sentidos sobre a Língua Portuguesa que são construídos nos dois documentos oficiais (PCN e BNCC) considerando-se que os PCN foram divulgados pelo MEC em 2009 e a BNCC, dez anos depois, em 2019. Ao escrever as considerações finais que dizem respeito aos questionamentos elaborados, a professora-pesquisadora nos indica que, "ao longo da pesquisa muitos sentidos foram descontruídos, reconstruídos, ressignificados, apagados, silenciados, enfim, muitos outros foram significados" (p. 190) e que passou a 


\section{OO DEVIR EDUCAÇÃO}

ISSN: 2526-849X

compreender um pouco mais acerca da importância da análise discursiva de documentos oficiais, arquivo, que prescrevem o ensino da língua no Brasil, como forma de evidenciar os deslizes de sentidos em relação à língua portuguesa como objeto de ensino de dominação e exploração, de relação de força (p. 185).

A partir deste excerto, destacamos a importância do mestrado profissional em educação como um importante espaço de formação de professores da Educação Básica, já que o professor-pesquisador "tem condições de ser protagonista de sua formação e transformação profissional" (Nogueira; Neres; Brito, 2016, p. 63) e de buscar novos conhecimentos em virtude das mudanças geradas pelas reformas educacionais. Além disso, ao analisarmos os questionamentos e as considerações finais a professora-pesquisadora indica que os sentidos pessoais foram ressignificados na medida em que passou a compreender melhor o objeto de sua pesquisa.

Já a professora-pesquisadora D2, ao questionar sobre o jogo e o conceito de número, apresenta-nos, em sua resposta, presente nas considerações finais, as relações que fez com os nexos conceituais (internos e externos) do conceito de número, tais como "noções de quantidade e qualidade, senso numérico, correspondência um-a-um, agrupamento e ordenação" (p. 91). Ao final da pesquisa enfatiza "que o trabalho pedagógico com o jogo de boliche na perspectiva $\mathrm{HC}^{6}$ pode reforçar e contribuir para o desenvolvimento mais efetivo das noções numéricas para crianças em estágio de educação infantil” (p. 91). Ressaltamos aqui a oportunidade, viabilizada pelo mestrado profissional em educação, de implementar a práticas formativas para que o docente possa atuar em sua realidade, em constante movimento, de modo a propiciar uma educação de qualidade para as crianças e os jovens que frequentam a escola (GATTI, 2010). Podemos inferir que a professora-pesquisadora consegue relacionar de forma direta o questionamento que fez com as considerações finais.

No caso da D3, a professora-pesquisadora questiona sobre as contribuições de uma proposta de formação colaborativa, baseada na reflexão sobre o ensino de Ciências na perspectiva Ciência, Tecnologia e Sociedade (CTS) e o desenvolvimento profissional docente. Ao tecer as considerações finais, ou seja, ao responder o questionamento feito, dá ênfase às seguintes contribuições:

o reconhecimento do processo de aprendizagem da docência como um continuum ao

\footnotetext{
${ }^{6}$ Histórico-cultural.
} 
longo da carreira; a importância da interação com pares que favorece a atribuição de significado para as novas experiências e as anteriores, ou seja, ao desenvolvimento profissional; o levantamento de problemas sobre a prática e a busca de soluções para as dificuldades enfrentadas; a promoção de reflexões de forma sistemática, rigorosa e disciplinada que exigem valorização de atitudes de ambas as partes - pesquisadora e professora; o encorajamento de situações inusitadas, incertas, conflituosas sobre novas formas de atuação (p. 89).

Neste caso, o mestrado profissional em educação "possibilita aos sujeitos um retorno ou continuidade de formação continuada que tem como um dos pontos cruciais a pesquisa e o ato reflexivo acerca, seja da sua prática, ou da realidade vivida; o que causa mudanças em sua prática docente" (OLIVEIRA; MOURA; SILVA, 2020, p. 417).

Ao analisar os dados referentes à relação entre o que os alunos estabelecem com a contextualização dos conteúdos da Física, a partir do questionamento que leva ao desenvolvimento de uma atividade experimental de investigação, a professora-pesquisadora D4, ao escrever sua resposta, nas considerações finais, prefere

separar as relações estabelecidas pelos estudantes de acordo com as perspectivas de contextualização: Aproximação com o cotidiano, Relação do conteúdo com outras áreas do conhecimento - Interdisciplinaridade e Busca por novos conhecimentos científicos. Essas categorias revelaram que os alunos estabeleceram uma certa relação com situações presentes em seus cotidianos, tentaram articular seus conhecimentos prévios com o fenômeno, os quais poderiam estar contextualizados também em outras disciplinas e para buscarem novos conhecimentos científicos (p. 62-63).

Entendemos, tal qual Pesce e André (2012, p. 49), que, na formação do professorpesquisador, no âmbito do mestrado profissional em educação, "saber diagnosticar, levantar hipóteses, buscar fundamentação teórica e analisar dados" são algumas das atividades que podem ajudar o trabalho do professor, dadas as exigências da realidade atual e a complexidade da função docente.

A professora-pesquisadora que escreveu a dissertação intitulada de D5, ao elaborar questionamentos sobre os limites e as possibilidades da interculturalidade como referencial de aulas de Arte no Ensino Médio afirma, em sua resposta, nas considerações finais "que durante as aulas foi possível trabalhar e valorizar os gostos dos alunos ao trabalhar com a realidade deles, discutir alteridade além de trabalhar a tolerância entre as opiniões” (p. 125). Ao mesmo 
tempo, chama a atenção para o fato de que "trabalhar buscando a interculturalidade no ensino exige muito estudo e análise da própria prática, pois muitas atitudes desfavorecem essa prática, por serem automáticas e passarem despercebidas em sala de aula" (p. 125). Salientamos neste excerto que o MPE da UFSCar promoveu os exercícios da reflexão na ação, bem como o da reflexão sobre a reflexão na ação, defendidos por Schön (1992), nos quais são considerados "a interculturalidade e a pluralidade como partes inerentes à sociedade e aos sujeitos" (FAGUNDES, 2016, p. 295).

E, por último, a professora-pesquisadora D6, ao questionar a trajetória identitária do diretor de escola negro quando num processo de assunção de um cargo de chefia em escolas municipais na cidade de São Paulo, indica, em sua resposta, nas considerações finais que a pesquisa "demonstra que a ascensão a cargos de chefia pela população negra é processual e necessária, as leis de reparação e ações afirmativas chegam com atraso, mas que bom que chegaram, pois a luta não termina com a promulgação da lei, e os dados que trouxemos até aqui demonstram essa perspectiva” (p. 150). Ressaltamos a postura do professor-pesquisador promovida pelo mestrado profissional em educação, referente às "lutas dos educadores e demais cidadãos em todos os lugares, visando uma vida mais igualitária em termos de meios e condições de vida" (REZENDE; OSTERMANN, 2015, p. 550).

Por fim, cabe destacar que, a partir da análise das relações aqui estabelecidas entre os questionamentos dos professores da Educação Básica no mestrado profissional em educação da UFSCar e as considerações finais tecidas em suas pesquisas, concordamos com André (2016) que a pesquisa parte dos problemas concretos do ensino, visa enfatizar a articulação entre teoria e prática assim como aproximar o universo acadêmico e o ensino nas escolas.

\section{Considerações finais}

Conforme apresentamos anteriormente, o mestrado profissional em educação tem se configurado no Brasil como um tipo de formação continuada. Sua especificidade está na abrangência das temáticas que podem ser estudadas.

Em decorrência, as pesquisas dos professores da Educação Básica que fazem parte do PPGPE, elaboradas no âmbito do mestrado profissional em educação da UFSCar, tratam tanto de temáticas que envolvem a formação de professores, quanto daquelas que se apresentam no cotidiano da escola, nos diversos níveis de ensino. São predominantemente qualitativas e se 
fundamentam em diversas perspectivas teóricas. Por este motivo, os professorespesquisadores produzem novos conhecimentos teóricos que consideram as linguagens da Arte; de Biologia, Ciências e Educação Ambiental; do Currículo; de Física; de Gestão; de Matemática e Pedagogia.

Dessa forma, durante o processo de elaboração das dissertações e, consequentemente, dos questionamentos e das considerações finais, os professores visam tornar-se autônomos e reflexivos no que diz respeito ao desenvolvimento de suas práticas. Nesse contexto, podem rever e teorizar o ensino que ministram, indicar os equívocos que se apresentam em propostas curriculares, compreender os conteúdos que são do interesse dos alunos e questionar os motivos pelos quais alguns temas são completamente desinteressantes aos alunos. Ou seja, as seis pesquisas, que tiveram os questionamentos e as respostas que foram elaboradas e que constam-nas considerações finais explicitam como os professores da Educação Básica refletem sobre suas próprias práticas, considerando-se que, assumem a realidade escolar como um objeto de pesquisa, de reflexão e de análise, segundo os pressupostos teóricos aqui apresentados. No entanto, é necessário ampliar os olhares e as discussões sobre as implicações práticas das pesquisas geradas nos cursos de Mestrado Profissional em Educação.

\section{Referências}

AMBROSETTI, Neusa Banhara; CALIL, Ana Maria Gimenes Corrêa. Contribuições do Mestrado Profissional em Educação para a formação docente. Reflexão e Ação, v. 24, n. 3, p. 85-104, 2016.

ANDRÉ, Marli. A formação do pesquisador da prática pedagógica. PLURAIS-Revista Multidisciplinar, v. 1, n. 1, 2016.

ANDRÉ, Marli; PRINCEPE, Lisandra. O lugar da pesquisa no Mestrado Profissional em Educação. Educar em Revista, n. 63, p. 103-117, 2017.

BRASIL. Ministério da Educação. Parecer CNE/CP 9/2001. Disponível em: http://portal.mec.gov.br/cne/arquivos/pdf/009.pdf. Acesso em 27/06/2020.

BRASIL. Ministério da Educação. Portaria Normativa nº 17, de 28 de dezembro de 2009. Dispõe sobre o mestrado profissional no âmbito da Fundação Coordenação de Aperfeiçoamento de Pessoal de Nível Superior - CAPES. Disponível em: https://www.capes.gov.br/images/stories/dowload/legislacao/PortariaNormativa_17MP.pdf. Acesso em: 10 mai. 2020.

FAGUNDES, Tatiana Bezerra. Os conceitos de professor pesquisador e professor reflexivo: 
perspectivas do trabalho docente. Revista Brasileira de Educação, Rio de Janeiro, v. 21, n. 65, p. 281-298. 2016.

FIALHO, Nadia Hage; HETKOWSKI, Tânia Maria. Mestrados Profissionais em Educação: novas perspectivas da pós-graduação no cenário brasileiro. Educar em Revista, Curitiba, n. 63, p. 19-34, 2017.

FIORENTINI, Dario; LORENZATO, Sergio. Investigação em Educação Matemática: percurso teóricos e metodológicos. $3^{\mathrm{a}}$ ed. Campinas: Autores Associados. 2007.

FREITAS, Helena C. L. de. A (nova) política de formação de professores: a prioridade postergada. Educação \& Sociedade, Campinas, v. 28, n. 100, p. 1203-1230, 2007 (Número especial).

GATTI, Bernardete. Formação de professores no Brasil: características e problemas. Educ. Soc., Campinas, v. 31, n. 113, p. 1355-1379, out.-dez. 2010.

LANNER DE MOURA, Anna Regina. A medida e a criança pré-escolar. 1995, 221f. Tese (Doutorado em Educação - Faculdade de Educação, UNICAMP).

LÜDKE, Menga; CRUZ, Giseli Barreto da; BOING, Luiz Alberto. A pesquisa do professor da educação básica em questão. Revista Brasileira de Educação, Rio de Janeiro, v. 14, n. 42, p. 456-468, 2009.

MOREIRA, Marco Antonio. Pesquisa em Ensino: o vê Epistemológico de Gowin. S.P., E.P.U., 1990.

NOGUEIRA, Eliane Davanço; NERES, Celi Corrêa; BRITO, Vilma Miranda. Mestrado profissional em educação: a constituição do professor/pesquisador e o retorno para a escola. Revista da FAEEBA-Educação e Contemporaneidade, Salvador, v. 25, n. 47, p. 63-75, 2016.

OLIVEIRA, Dayse Kelly Barreiros; MOURA, Ellen Michelle Barbosa; SILVA, Kátia Augusta Pinheiro Cordeiro Curado. Mestrado Profissional: perspectiva de formação continuada stricto sensu para o professor da educação. Pensar Acadêmico, Coqueiro Manhuaçu/MG, v. 18, n. 2, p. 401-425, 2020.

PESCE, Marly Krüger; ANDRÉ, Marli Elisa Dalmazo Afonso. Formação do professor pesquisador na perspectiva do professor formador. Formação Docente-Revista Brasileira de Pesquisa sobre Formação de Professores, Belo Horizonte, v. 4, n. 7, p. 39-50, 2012.

REZENDE, Flavia; OSTERMANN, Fernanda. O protagonismo controverso dos mestrados profissionais em ensino de ciências. Ciência \& Educação (Bauru), v. 21, n. 3, p. 543-558, 2015.

RIBEIRO, Renato Janine. O mestrado profissional na política atual da Capes. Revista Brasileira de Pós-Graduação, v. 2, n. 4, p. 8-15, 2005. 
RIBEIRO, Renato Janine. Ainda sobre o mestrado profissional. RBPG, Brasília, v. 3, n. 6, p. 313-315, dez. 2006. Seção Debates.

SCHÖN, Donald. The reflective practitioner. Nova York: Basic Books, 1983.

SCHÖN, Donald. Formar professores como profissionais reflexivos. In: Nóvoa, A. (Org.). Os professores e a sua formação. Lisboa: Dom Quixote, 1992. p. 79-91.

SILVA, Kátia Augusta Pinheiro Cordeiro Curado. Epistemologia da práxis na formação de professores: perspectiva crítico emancipadora. Revista de Ciências Humanas, Florianópolis, v. 18, n. 02, p. 121-135, 2017.

STENHOUSE, Lawrence. An introduction to curriculum research and development. Londres: Heinemann, 1975.

STENHOUSE, Lawrence. Investigación y desarrollo del curriculum. Madrid: Morata, 1981.

UFSCar. Projeto Pedagógico do Curso, 2020. Disponível em: http://www.ppgpe.ufscar.br/

Recebido em: 29/06/2020

Aprovado em: 10/08/2020

Revista Devir Educação, Lavras, vol.2, n.4, p.104-125 jul./dez., 2020. 